\title{
Asthma and Injury Risk: A Large Scale Population-Based Study
}

\author{
Wenbin Liang*, Tanya Chikritzhs \\ National Drug Research Institute, Curtin University, Perth, Australia. \\ Email: *w.liang@curtin.edu.au \\ Received May $11^{\text {th }}, 2012$; revised June $16^{\text {th }}, 2012$; accepted July $18^{\text {th }}, 2012$
}

\begin{abstract}
Purpose: Clinical data suggest that asthma impairs sleep quality and further impairs cognitive performance during the daytime, while there is a causal relationship between impaired sleep quality and injuries. Therefore asthma patients may have increased risk of injury, and this is supported by our recent population-based studies conducted in Australia. This study is to investigate the effect of asthma on the risk of injury at the population level using data from the US National Health Interview Survey collected in 2008, 2009, and 2010. Method: Data from the 2008, 2009 and 2010 National Health Interview Surveys were combined and analyzed together. Results: US adults with current or previous asthma had significantly greater risk of injury compared to those without asthma. The risk of injury was also significantly higher among children with current asthma. Conclusion: This population-based study provided further evidence on the positive association between asthma and risk of injury among both adults and children. The increased risk of injury among asthma patients is at least partly due to impaired sleep quality and quantity caused by asthma symptoms and asthma medications.
\end{abstract}

Keywords: Asthma; Sleep; Injury

\section{Introduction}

Asthma is one of the major public health problems that affect both children and adults in many different populations among both industrialized and developing nations [1-3]. Parallel with urbanization, the prevalence of asthma has been increasing in all countries over the past 40 years. In 2004, it was estimated that asthma affected 300 million people worldwide, [4] and it caused around 250,000 deaths in 2007 [5]. Clinical data suggest that asthma impairs sleep quality and further impairs cognitive performance during the daytime, especially among those with serious night-time symptoms [6-10]. There is a causal relationship between impaired sleep quality and injuries [11,12]. Moreover, it has also been shown that asthma patients are at higher risk of fracture due to reduced bone mass and bruising, [13,14] a known side effect of corticosteroid medication. Our recent population-based studies suggest that a history of asthma is associated with an increased risk of injury from various causes and types among Australian children and adults $[15,16]$. Both of our previous studies were performed on Australian populations, and it is necessary to reassess the associations in other regions through large scale popula-

*Corresponding author. tion-based studies.

Asthma has high prevalence in the United States [1]. The National Health Interview Surveys (NHIS) collect information on both asthma status and injuries, this has provided an opportunity to investigate the association between asthma status and injuries with a large sample representative of the US population. Data were obtained through Internet release of the NHISs data at

http://www.cdc.gov. The present study aimed to investigate the effect of asthma on the risk of injury at the population level using data from the National Health Interview Survey (NHIS) collected in 2008, 2009, and 2010.

\section{Method}

Data from the 2008, 2009 and 2010 National Health Interview Surveys (NHISs) were combined and analyzed together. Details of the survey sampling strategy and data collection methods have been described elsewhere [1719]. Briefly, the NHISs are nationally focused and conducted by the National Center for Health Statistics (NCHS), Centers for Disease Control and Prevention (CDC). The 2008, 2009 and 2010 NHISs used the same sample design as the 2006 NHIS survey. The NHISs were conducted to provide comprehensive estimations of 
health indictors at a national level, state stratified samples were draw from all 50 states and the District of Columbia to ensure the samples are representative at state level [17-19]. Households were the basic unit of the NHIS. For each selected household, if there were more than one family residing in a household, all families in the household were selected, and assigned a unique family number. NHIS collected basic demographics, health status (including injuries and poisoning incidences over the last three months), use of health services for each family member, and health information (including asthma history) of one random selected adult and one random selected child ( $<18$ years) if there were children living in the family. Information was collected via computer-assisted face-to-face interviews. Since asthma histories were only collected from one randomly selected adult and one child within the family (rather than every person in the family), this study included all selected adults and children from the three waves of the NHIS [17-19].

Defining asthma status: Both of sample adults and sample children were asked whether they had ever been told they had asthma by a doctor or nurse. Participants with positive responses were further asked whether their asthma was current. Based on the answers to these two questions asthma status was classified into one of three categories (without asthma; previous asthma; current). Defining injuries and poisoning: The NHISs recorded every reported injury which occurred in the three-month period prior to the interview and required a medical consultation (i.e. call to a poison control center; use of an emergency vehicle or emergency room; visit to a doctor's office). The current study included all recorded injuries and poisoning events which occurred to the sample adults and sample children. Demographics of participants extracted from the datasets and controlled for in the analysis included: age, sex, race, marital status (adults only), education level of the adult with the highest education in family and ratio of family income to the poverty threshold. Multivariate Poisson regression with robust estimation of variance was used to investigate the asso- ciation between asthma status and the risk of injuries, with analyses performed separately for adults and children. The sampling weight was used in all multivariate analyses. Missing values of some selected family demographic variables were observed in about $10 \%$ of the total 76,669 adult participants and 8\% of the total 31,248 child participants. Variables with missing values were: 1) marital status (adult only); 2) education of adult with highest education in the family; and 3) ratio of family income to the poverty threshold. Imputation was used to produce estimations for the cells with missing values. Ten imputations were produced. The first set of Poisson models were performed while excluding observations with missing values. Then the second set of Poisson models were refitted with imputed estimations. All analysis was performed with STATA ${ }^{\circledR} 11$.

\section{Results}

The adult sample included 76,669 participants. The approximate crude accumulative incidence rates of adult injury for 1) adults with current asthma; 2) adults who previously had asthma; and 3) adults who never had asthma, were, 222 per 1000 person-years, 153 per 1000 person-years and 111 per 1000 person-years respectively. The crude relative risks were significantly different with the risk of injury among participants with current asthma twice as great as those who never had asthma (Table 1). In the multivariate analysis, most of the control variables were significantly associated with the risk of injury, however, the effects of asthma status on the risk of injury appeared to be largely independent of the control variables (Table 2). The multivariate relative risk estimates for injury across the three categories of asthma status were similar to those obtained in the univariate analysis.

The child sample included 31,248 participants. The approximate crude accumulative incidence rates of child injury for 1) children with current asthma; 2) children who previously had asthma; and 3) children who never had asthma, were, 169 per 1000 person-years, 126 per 1000 person-years and 100 per 1000 person-years

Table 1. numbers of injuries, participants and relative risk by asthma status.

\begin{tabular}{|c|c|c|c|c|c|}
\hline Asthma status & Injuries (N) & Participants (N) & Rate Ratio & \multicolumn{2}{|c|}{$95 \%$ CI } \\
\hline Never had asthma & 1858 & 67,008 & 1.00 & & \\
\hline Ever had asthma & 140 & 3670 & 1.38 & 1.15 & 1.65 \\
\hline Current asthma & 333 & 5991 & 2.00 & 1.75 & 2.29 \\
\hline \multicolumn{6}{|l|}{ Children } \\
\hline Never had asthma & 669 & 26,869 & 1.0 & & \\
\hline Ever had asthma & 44 & 1402 & 1.26 & 0.93 & 1.71 \\
\hline Current asthma & 126 & 2977 & 1.70 & 1.38 & 2.10 \\
\hline
\end{tabular}


Table 2. Estimations from multivariate Poisson regression model: The association between asthma status and risk of injury in adults.

\begin{tabular}{|c|c|c|c|c|c|c|}
\hline & \multicolumn{3}{|c|}{ Without imputation } & \multicolumn{3}{|c|}{ With imputation } \\
\hline & Rate Ratio & $95 \%$ & CI & Rate Ratio $^{*}$ & $95 \%$ & CI \\
\hline \multicolumn{7}{|l|}{ Asthma status } \\
\hline Never had asthma & 1.00 & & & 1.00 & & \\
\hline Ever had asthma & 1.26 & 1.01 & 1.56 & 1.31 & 1.06 & 1.63 \\
\hline Current asthma & 1.81 & 1.54 & 2.13 & 1.86 & 1.59 & 2.17 \\
\hline \multicolumn{7}{|l|}{ Sex } \\
\hline Male & 1.00 & & & 1.00 & & \\
\hline Female & 0.95 & 0.84 & 1.06 & 0.93 & 0.83 & 1.03 \\
\hline \multicolumn{7}{|l|}{ Age group } \\
\hline $18-24$ & 1.00 & & & 1.00 & & \\
\hline $35-44$ & 1.05 & 0.80 & 1.37 & 1.06 & 0.81 & 1.39 \\
\hline $45-54$ & 1.14 & 0.87 & 1.48 & 1.10 & 0.85 & 1.42 \\
\hline $55-64$ & 1.18 & 0.90 & 1.54 & 1.19 & 0.92 & 1.55 \\
\hline $65+$ & 1.30 & 0.97 & 1.72 & 1.26 & 0.96 & 1.66 \\
\hline \multicolumn{7}{|l|}{ Race } \\
\hline White & 1.00 & & & 1.00 & & \\
\hline Black & 0.79 & 0.66 & 0.95 & 0.80 & 0.67 & 0.95 \\
\hline Other & 0.80 & 0.62 & 1.04 & 0.84 & 0.66 & 1.07 \\
\hline \multicolumn{7}{|l|}{ Marital status } \\
\hline Married or de facto & 1.00 & & & 1.00 & & \\
\hline \multicolumn{7}{|c|}{ Ratio of family income to the poverty threshold } \\
\hline Less than 1 & 1.00 & & & 1.00 & & \\
\hline $1-1.99$ & 0.85 & 0.70 & 1.03 & 0.86 & 0.72 & 1.03 \\
\hline $2.0+$ & 0.88 & 0.75 & 1.03 & 0.90 & 0.77 & 1.06 \\
\hline \multicolumn{7}{|c|}{ Educational level attained for adult with highest education in the family } \\
\hline 12 grade or less & 1.00 & & & 1.00 & & \\
\hline Had some college & 1.25 & 1.03 & 1.53 & 1.19 & 0.99 & 1.43 \\
\hline With a degree or above & 1.26 & 1.02 & 1.55 & 1.19 & 0.98 & 1.44 \\
\hline \multicolumn{7}{|c|}{ Whether any family member had delayed medical care in the last 12 months } \\
\hline No & 1.00 & & & 1.00 & & \\
\hline Yes & 1.35 & 1.19 & 1.54 & 1.36 & 1.20 & 1.54 \\
\hline \multicolumn{7}{|l|}{ Year of survey } \\
\hline 2008 & 1.00 & & & 1.00 & & \\
\hline 2009 & 1.06 & 0.92 & 1.22 & 1.05 & 0.92 & 1.20 \\
\hline 2010 & 0.98 & 0.86 & 1.13 & 0.98 & 0.86 & 1.12 \\
\hline
\end{tabular}

*IRR: incidence rate ratio.

respectively. Compared to participants without asthma, the risk of injury was significantly (70\%) higher for those children with current asthma but not for those with previous asthma (Table 1). As found for the adult sample, in the multivariate analysis, most of the control variables were significantly associated with risk of injury, however, the risk of injury remained significantly higher (50\%) for children with current asthma compared to those without 
(Table 3). Estimations from the analysis of the original data and estimations from the analysis with multiple imputations were found to be very similar.

\section{Discussion}

In this large scale population-based study, US adults with current or previous asthma had significantly greater risk of injury compared to those without asthma. The risk of injury was also significantly higher among children with current asthma. The association between asthma status and risk of injury was largely unaffected by the inclusion of control variables. These observations are consistent with findings from previous studies [15,16, 20-22]. In our recent birth cohort study conducted in Western Australia, it was observed that for both children and adults, males with histories of hospitalizations of asthma were at increased risk of serious injury (injuries that required hospitalizations) [16].

Table 3. Estimations from multivariate Poisson regression model: The association between asthma status and risk of injury in children.

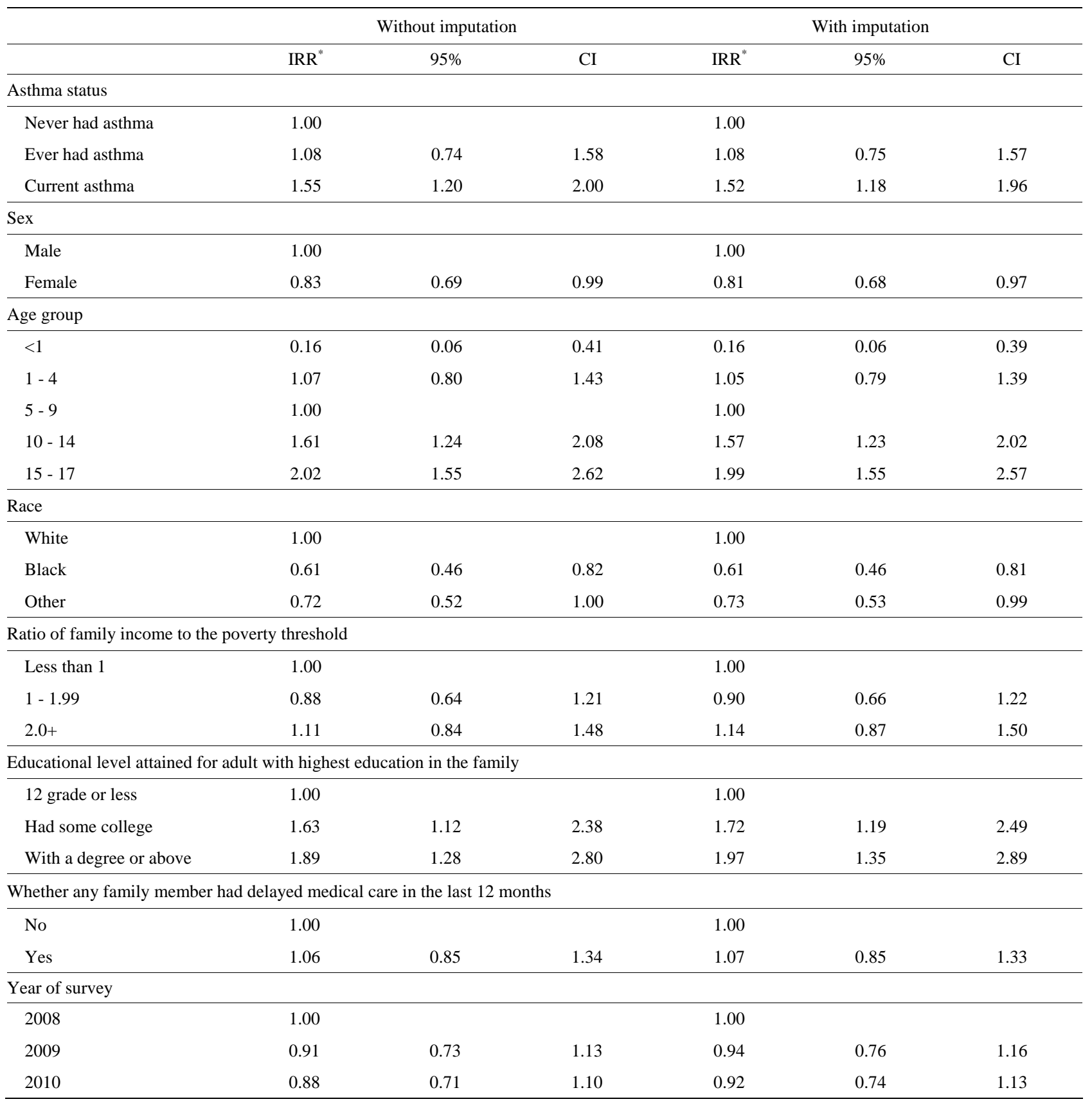

*IRR: incidence rate ratio. 
The mechanism(s) underlying this association is not entirely clear, however, it is likely to be causal. Asthmatic conditions and the medications used to treat asthma (including corticosteroids) may impair the mental function of patients and alter their responses to hazard, and further increase the risk of injury. Among the participants of the current study, adults with current asthma or previous asthma were more likely to sleep less than 7 hours every 24 hours at the time of survey compared to those without asthma (37\%, 32\% and 28\%, respectively, $\mathrm{p}$ value of Pearson chi-square test $<0.001$ ). Previous research has suggested that asthma patients are more likely to experience sleepiness during daytime hours $[7,23,24]$ and that asthma condition and medications for asthma may impair sleep quality $[8,25]$. Moreover, there is substantial evidence suggesting that daytime sleepiness, inadequate sleep or poor sleep quality is an independent risk factor for injuries in both adults and children [11, 12,26-29]. Combining the evidence on the three relationships: 1) asthma status and injury; 2) asthma status and its impairment on sleep quality and quantity and 3) inadequacy of sleep and injury, indicates a direct link between asthma status and injury mediated through impaired sleep quality and quantity. Interventions that improve sleep among asthma patients are likely further reduce the risk of injury among these patients.

\section{Conclusion}

This population-based study provided further evidence on the positive association between asthma and risk of injury among both adults and children. It is highly likely that the increased risk of injury among asthma patients is at least partly due to impaired sleep quality and quantity caused by asthma symptoms and asthma medications. To reduce the risk of injury among asthmatics, interventions are required which improve sleep quality and quantity among patients.

\section{REFERENCES}

[1] W. Eder, M. J. Ege and E. von Mutius, "Current Concepts: The Asthma Epidemic," New England Journal of Medicine, Vol. 355, No. 21, 2006, pp. 2226-2235. doi:10.1056/NEJMra054308

[2] G. Russell, "The Childhood Asthma Epidemic," Thorax, Vol. 61, No. 4, 2006, pp. 276-278. doi:10.1136/thx.2005.052662

[3] S. P. Peters, G. Ferguson, Y. Deniz and C. Reisner, "Uncontrolled Asthma: A Review of the Prevalence, Disease Burden and Options for Treatment," Respiratory Medicine, Vol. 100, No. 7, 2006, pp. 1139-1151. doi:10.1016/j.rmed.2006.03.031

[4] M. Masoli, D. Fabian, S. Holt and R. Beasley, "The Global Burden of Asthma: Executive Summary of the GINA Dissemination Committee Report,” Allergy, Vol.
59, No. 5, 2004, pp. 469-478. doi:10.1111/j.1398-9995.2004.00526.x

[5] WHO, "Global Surveillance, Prevention and Control of Chronic Respiratory Diseases: A Comprehensive Approach,” World Health Organization, Geneva, 2007.

[6] G. B. Diette, L. Markson, E. A. Skinner, T. T. H. Nguyen, P. Algatt-Bergstrom and A. W. Wu, "Nocturnal Asthma in Children Affects School Attendance, School Performance, and Parents' Work Attendance," Archives of Pediatrics \& Adolescent Medicine, Vol. 154, No. 9, 2000, pp. 923-928.

[7] M. F. Fitzpatrick, H. Engleman, K. F. Whyte, I. J. Deary, C. M. Shapiro and N. J. Douglas, "Morbidity in Nocturnal Asthma: Sleep Quality and Daytime Cognitive Performance,” Thorax, Vol. 46, No. 8, 1991, pp. 569-573. doi:10.1136/thx.46.8.569

[8] M. Teodorescu, F. B. Consens, W. F. Bria, M. J. Coffey, M. S. McMorris, K. J. Weatherwax, et al., "Correlates of Daytime Sleepiness in Patients with Asthma," Sleep Medicine, Vol. 7, No. 8, 2006, pp. 607-613. doi:10.1016/j.sleep.2006.02.001

[9] C. Janson, W. De Backer, T. Gislason, P. Plaschke, E. Bjornsson, J. Hetta, et al., "Increased Prevalence of Sleep Disturbances and Daytime Sleepiness in Subjects with Bronchial Asthma: A Population Study of Young Adults in Three European Countries," European Respiratory Journal, Vol. 9, No. 10, 1996, pp. 2132-2138. doi:10.1183/09031936.96.09102132

[10] F. L. Campos, F. P. da Silva-Júnior, V. M. S. de Bruin and P. F. C. de Bruin, "Melatonin Improves Sleep in Asthma," American Journal of Respiratory and Critical Care Medicine, Vol. 170, No. 9, 2004, pp. 947-951. doi:10.1164/rccm.200404-4880C

[11] M. Daley, C. M. Morin, M. LeBlanc, J. P. Grégoire, J. Savard and L. Baillargeon, "Insomnia and Its Relationship to Health-Care Utilization, Work Absenteeism, Productivity and Accidents,” Sleep Medicine, Vol. 10, No. 4, 2009, pp. 427-438. doi:10.1016/j.sleep.2008.04.005

[12] J. A. Owens, S. Fernando and M. McGuinn, "Sleep Disturbance and Injury Risk in Young Children,” Behavioral Sleep Medicine, Vol. 3, No. 1, 2005, pp. 18-31. doi:10.1207/s15402010bsm0301_4

[13] A. D. Adinoff and J. R. Hollister, "Steroid-Induced Fractures and Bone Loss in Patients with Asthma," New England Journal of Medicine, Vol. 309, No. 5, 1983, pp. 265-268. doi:10.1056/NEJM198308043090502

[14] R. Dahl, "Systemic Side Effects of Inhaled Corticosteroids in Patients with Asthma," Respiratory Medicine, Vol. 100, No. 8, 2006, pp. 1307-1317. doi:10.1016/j.rmed.2005.11.020

[15] W. Liang, T. Chikritzhs and A. H. Lee, "Is Asthma Associated with Increased Risk of Injury?” Journal of Asthma, Vol. 48, No. 3, 2011, pp. 311-315. doi:10.3109/02770903.2011.554945

[16] W. Liang, T. Chikritzhs and A .H. Lee, “Asthma and Risk of Injury for Australian Males Aged 6 - 30 Years: A Population-Based Birth Cohort Study," Journal of Asthma, Vol. 48, No. 7, 2011, pp. 736-740. doi:10.3109/02770903.2011.599910 
[17] CDC, “2010 NHIS Survey Description,” Centers for Disease Control and Prevention, US Department of Health and Human Services, Maryland, 2011.

[18] CDC, “2008 NHIS Survey Description,” Centers for Disease Control and Prevention, US Department of Health and Human Services, Maryland, 2009.

[19] CDC, “2009 NHIS Survey Description,” Centers for Disease Control and Prevention, US Department of Health and Human Services, Maryland, 2010.

[20] H. Y. Xiang, L. Stallones, G. M. Chen, S. G. Hostetler and K. Kelleher, "Nonfatal Injuries among US Children with Disabling Conditions," American Journal of Public Health, Vol. 95, No. 11, 2005, pp. 1970-1975. doi:10.2105/AJPH.2004.057505

[21] L.-C. Lee, R. A. Harrington, J. J. Chang and S. L. Connors, "Increased Risk of Injury in Children with Developmental Disabilities," Research in Developmental Disabilities, Vol. 29, No. 3, 2007, pp. 247-255. doi:10.1016/j.ridd.2007.05.002

[22] D. C. Schwebel and C. M. Brezausek, "Injury Risk in Children with Asthma,” Journal of Asthma, Vol. 46, No. 6, 2009, pp. 560-563. doi:10.1080/02770900902866750

[23] C. Janson, T. Gislason, G. Boman, J. Hetta and B. E. Roos, "Sleep Disturbances in Patients with Asthma," Respiratory Medicine, Vol. 84, No. 1, 1990, pp. 37-42. doi:10.1016/S0954-6111(08)80092-3
[24] M. E. Klink, R. Dodge and S. F. Quan, “The Relation of Sleep Complaints to Respiratory Symptoms in a General Population,” Chest, Vol. 105, No. 1, 1994, pp. 151-154. doi:10.1378/chest.105.1.151

[25] J. G. Mastronarde, R. A. Wise, D. M. Shade, C. O. Olopade, , S. M. Scharf and f.t.A.L.A.A.C.R. Centers, "Sleep Quality in Asthma: Results of a Large Prospective Clinical Trial,” Journal of Asthma, Vol. 45, No. 3, 2008, pp. 183-189. doi:10.1080/02770900801890224

[26] S. Melamed and A. Oksenberg, "Excessive Daytime Sleepiness and Risk of Occupational Injuries in Non-Shift Daytime Workers," Sleep, Vol. 25, No. 3, 2002, pp. 315-322.

[27] J. Terán-Santos, A. Jimenez-Gomez and J. CorderoGuevara, "The Association between Sleep Apnea and the Risk of Traffic Accidents," New England Journal of Medicine, Vol. 340, No. 11, 1999, pp. 847-851. doi:10.1056/NEJM199903183401104

[28] D. R. Gold, S. Rogacz, N. Bock, T. D. Tosteson, T. M Baum, F. E. Speizer, et al., "Rotating Shift Work, Sleep, and Accidents Related to Sleepiness in Hospital Nurses," American Journal of Public Health, Vol. 82, No. 7, 1992, pp. 1011-1014. doi:10.2105/AJPH.82.7.1011

[29] F. Valent, S. Brusaferro and F. Barbone, "A CaseCrossover Study of Sleep and Childhood Injury," Pediatrics, Vol. 107, No. 2, 2001, p. e23. doi:10.1542/peds.107.2.e23 